http://dx.doi.org/10.35381/r.k.v5i4.954

\title{
Estrategias tributarias como herramientas de optimización de rentabilidad en el sector de alquiler de vehículos
}

Tax strategies as tools to optimize profitability in the car rental sector

\author{
José Marcelo Casal-Abril \\ jose.casal41@est.ucacue.edu.ec \\ Universidad Católica de Cuenca, Cuenca \\ Ecuador \\ https://orcid.org/0000-0002-9666-4738 \\ Jorge Edison Becerra-Molina \\ jbecerram@ucacue.edu.ec \\ Universidad Católica de Cuenca, Cuenca \\ Ecuador \\ https://orcid.org/0000-0002-6397-9493 \\ Lenyn Geovanny Vásconez-Acuña \\ lenyn.vasconez@ucacue.edu.ec \\ Universidad Católica de Cuenca, Cuenca \\ Ecuador \\ https://orcid.org/0000-0001-9258-3255
}

Recibido: 01 de junio de 2020

Revisado: 20 de junio de 2020

Aprobado: 02 de septiembre de 2020

Publicado: 24 de septiembre de 2020 


\title{
RESUMEN
}

La investigación se planteó como objetivo diseñar estrategias tributarias que permitan el incremento de la liquidez y rentabilidad en las empresas de alquiler de vehículos de la ciudad de Cuenca. Se situó en una tipología descriptiva documental con diseño de campo de no experimental. La propuesta de diseñar estrategias tributarias como herramientas de optimización de rentabilidad, busca identificar las exenciones y deducciones contempladas en la Ley Orgánica de Régimen Tributario Interno que las empresas de alquiler de vehículos deben utilizar para beneficiarse de un menor pago del impuesto a la renta. Por medio del diseño de estas estrategias se pretende disminuir la carga de impuestos de una manera licita sin caer en la elusión o evasión de impuestos que son sancionadas por la ley, sino más bien, consiste en utilizar los medios que brinda el ordenamiento jurídico o de una deficiencia en la norma.

Descriptores: Financiación; tributación; empresa; crecimiento económico; planificación estratégica. (Palabras tomadas del Tesauro UNESCO).

\begin{abstract}
The objective of the research was to design tax strategies that allow the increase of liquidity and profitability in the car rental companies of the city of Cuenca. It was located in a descriptive documentary typology with a non-experimental field design. The proposal to design tax strategies as profitability optimization tools seeks to identify the exemptions and deductions contemplated in the Organic Law of Internal Tax Regime that vehicle rental companies must use to benefit from a lower income tax payment. Through the design of these strategies, it is intended to reduce the tax burden in a lawful way without falling into the avoidance or evasion of taxes that are sanctioned by law, but rather, it consists of using the means provided by the legal system or a deficiency in the standard.
\end{abstract}

Descriptors: Financing; taxation; enterprises; economic growth; strategic planning. (Words taken from the UNESCO Thesaurus). 


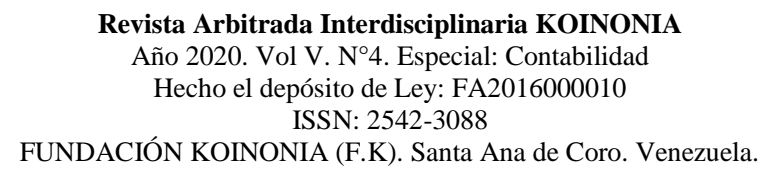

José Marcelo Casal-Abril; Jorge Edison Becerra-Molina; Lenyn Geovanny Vásconez-Acuña

\section{INTRODUCCIÓN}

Uno de los mayores problemas que tienen las pequeñas y medianas empresas (Pymes) en Latinoamérica, según (González, 2015) consiste en la adquisición de recursos por medio de financiamiento externo para saldar las operaciones e iniciar proyectos que favorezcan el adelanto y crecimiento de los negocios. Las limitaciones que se encuentran en el proceso de financiamiento causan que estas empresas permanezcan entorpecidas en los procedimientos de productividad sin posibilidad alguna de crecimiento; ante esto, se han visto en el menester de replantear sus estrategias con la finalidad de enfrentar estos factores que son propios de la globalización (García et al., 2015).

Del mismo modo, (Bohórquez, et al., 2018) indican que las Pymes en el Ecuador enfrentan problemas relacionados con el financiamiento, entre ellos la desconfianza de la banca para otorgar préstamos aun cuando ocupan un sitial importante en la economía ecuatoriana, sumado el descuido de los propietarios y la carencia de visión de las empresas en financiamiento en el largo plazo. Por otro lado, el alto impacto tributario no permite a estas empresas un crecimiento de forma sostenida, debido a las distintas leyes promulgadas por parte de los gobernantes de acuerdo con las circunstancias (Soto, 2018).

Se manifiesta también, que por varios años la falta de conocimiento de las obligaciones tributarias ha sido un gran problema, estudios realizados en distintos países de Latinoamérica, en especial en Ecuador, ponen en evidencia esta problemática, que conlleva a que una gran cantidad de negocios cierren y cancelen fuertes multas o sanciones por incumplimiento de sus obligaciones tributarias (Veloz-García, 2018).

Con respecto al crecimiento empresarial, (Daza-Izquierdo, 2016) manifiestan que el crecimiento establece el esparcimiento que ejecuta un organismo empresarial en torno a nuevas áreas de emprendimientos, consintiendo que la organización obtenga un mejor personal y los preserve para formar una causa de provecho para la competencia en el mercado. En este contexto, las empresas de alquiler de vehículos de la ciudad de Cuenca con la finalidad de lograr un crecimiento sostenible buscan financiamiento en las 


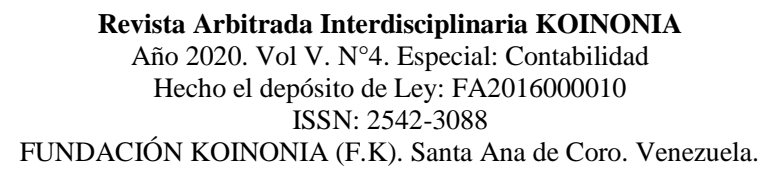

José Marcelo Casal-Abril; Jorge Edison Becerra-Molina; Lenyn Geovanny Vásconez-Acuña

entidades bancarias para solventar las operaciones propias del giro de su negocio, sin embargo, por las características y naturaleza de su estructura son consideradas como empresas de alto riesgo, en consecuencia, el sistema financiero en su mayoría prefiere colocar sus recursos económicos en entidades de mayor tamaño.

Por otro lado, a pesar de la consolidación del sistema tributario ecuatoriano con el paso del tiempo, el evadir por incomprensión los tributos se ha convertido en una dificultad esencial en el país, las Pymes en general, para realizar sus declaraciones no cuentan con un sustento contable que afiance su gestión tributaria, situación que conlleva a la identificación de errores u omisiones en los documentos de apoyo por parte de la administración tributaria lo que genera sanciones a los contribuyentes ocasionando la interrupción de las actividades según la falta cometida.

Ante lo expuesto, surge el siguiente problema de investigación: ¿Cómo incide el financiamiento y planificación tributaria en la determinación del crecimiento de las empresas de alquiler de vehículos de la ciudad de Cuenca?; en consecuencia, en la investigación se planteó como objetivo diseñar estrategias tributarias que permitan el incremento de la liquidez y rentabilidad en las empresas de alquiler de vehículos de la ciudad de Cuenca.

\section{Referencial teórico}

Responsabilidad tributaria: dimensiones, componentes y planificación de los tributos

En este sentido, (Amasifuen, 2015) manifiesta que la responsabilidad tributaria es el conjunto de supuestos básicos de conducta de una población que asume lo que se debe y no se debe hacer con relación al pago de tributos en un país y está determinada por dos aspectos, uno de tipo legal y otro de tipo ideológico; el primero tiene que ver con la dificultad que existe en el incumplimiento de las obligaciones motivo por el que puede ser sancionado y el segundo con la complacencia en la urbe por la utilización correcta de 
los recursos que son aportados y le son devueltos mediante obras de servicio público apropiadas.

La responsabilidad tributaria según los autores (Sarduy-González \& Gancedo-Gaspar, 2016), se relaciona de manera directa con principios de ética y moral; aspectos sociales y culturales; el grado de conocimientos que tienen los contribuyentes en cuanto a sus deberes, obligaciones y derechos, el discernimiento que tiene el ciudadano de la forma en que se administran los tributos recaudados por parte del Estado. De acuerdo con la (Registro Oficial Suplemento 38 de 14-jun.-2005), en el artículo 1 del Código Tributario se entiende por tributos a los impuestos, tasas y contribuciones especiales, por lo tanto podemos indicar: los impuestos son tributos recaudados y regentados por el Servicio de Rentas Internas en el Ecuador, los mismos que son cancelados por los contribuyentes de acuerdo a lo que establece la ley; las tasas son tributos que cancelan los usuarios por el uso de una prestación recibida del Estado, no es considera como impuesto.

En tanto que, las contribuciones especiales hacen referencia a sumas de dinero que el Estado o ente recaudador exige en razón de la ejecución de una obra pública, su realización o construcción debe proporcionar un beneficio económico en el patrimonio del contribuyente. El artículo 6 del Código Tributario señala que:

Los tributos servirán como instrumento de política económica general, estimulando la inversión, la reinversión, él ahorro y su destino hacia los fines productivos y de desarrollo nacional; atenderán a las exigencias de estabilidad y progreso sociales y procurarán una mejor distribución de la renta nacional. (Registro Oficial Suplemento 38 de 14-jun.-2005, p.2).

Según el artículo 15 del Código Tributario la obligación tributaria, es la relación que existe de manera jurídica personal entre el Estado o entidades autorizadas para la captación de tributos y las personas que realizan estos pagos, en el que se satisface un impuesto en efectivo, especies o servicios perceptibles en dinero, cuando se produce el hecho generador dispuesto en la ley (Registro Oficial Suplemento 38 de 14-jun.-2005).

Se interpreta al hecho generador según el artículo 16 del Código Tributario al presupuesto instaurado en la ley para estructurar cada tributo; cuando este hecho se sustente en un 
acto jurídico, se calificará acorde a su genuina índole y naturaleza jurídica, mediante el medio elegido o la denominación seleccionada por los interesados. Cuando este hecho se refiera a conceptos económicos, se tendrá en consideración las situaciones o vínculos económicos que existan o se instauren por parte de los interesados, de manera independiente a las formas jurídicas que sean utilizadas.

Por otra parte, el artículo 18 del Código Tributario manifiesta que la obligación tributaria se origina cuando se elabora el presupuesto implantado por la ley para configurar el tributo y se lo debe cobrar a partir de la fecha que la ley establezca para el efecto, es decir, en el momento que se crea el hecho generador establecido en la ley (Ibídem). El Código Tributario en el artículo 25 indica:

Contribuyente es la persona natural o jurídica a quien la ley impone la prestación tributaria por la verificación del hecho generador. Nunca perderá su condición de contribuyente quien, según ley, deba soportar la carga tributaria, aunque realice su traslación a otras personas. (Registro Oficial Suplemento 38 de 14-jun.-2005).

Los individuos nacionales y extranjeros que efectúan actividades económicas en el Ecuador y obtienen ingresos de su trabajo particular son considerados personas naturales; esta clase de contribuyente se subdivide en obligados a llevar contabilidad o no obligados a llevar contabilidad dependiendo del límite de ingresos brutos, capital o gastos del ejercicio inmediato anterior. Así también, se entiende por personas jurídicas a todas las compañías limitadas, sociedades anónimas o de hecho que realizan actividades económicas en el país; las que en su totalidad se encuentran reguladas por la Superintendencia de Compañías, Valores y Seguros.

La base imponible según el artículo 16 de la Ley Orgánica de Régimen Tributario Interno (LORTI), hace referencia al importe sobre el que se va a desarrollar el cálculo del tributo a ser cancelado, está compuesta por la totalidad de los ingresos recibidos por una persona natural o jurídica sean estos ordinarios o extraordinarios gravados con el impuesto; menos las devoluciones, descuentos, costos, gastos y deducciones aplicables a estos ingresos (Registro Oficial Suplemento 463 de 17-nov-2014). 


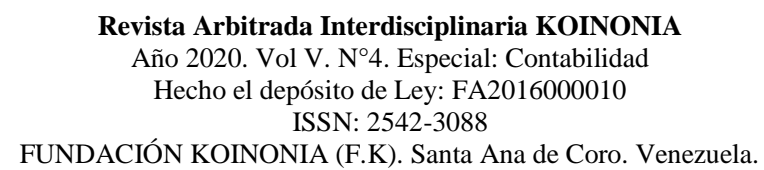

José Marcelo Casal-Abril; Jorge Edison Becerra-Molina; Lenyn Geovanny Vásconez-Acuña

La planificación tributaria según (Báez, 2016), es un proceso en el que los contribuyentes prevén situaciones propias del giro de su negocio con el objetivo de postergar o evitar una futura obligación tributaria mediante el adecuado cumplimiento de estrategias que estén apegadas a la ley, por su parte, (Castañeda-Rodríguez, 2017) manifiestan que la planificación tributaria es un instrumento en el que por medio del estudio de la normativa y la determinación de beneficios tributarios se optimiza el impuesto fiscal sin que esto sea considerada una conducta ilegal, con el propósito de optar por alternativas legales que posibiliten el ahorro tributario.

En lo concerniente, a las limitantes de la planificación tributaria se encuentra la elusión y evasión, (Matus-Fuentes, 2017) interpreta a la elusión como el acto donde se apañan actos jurídicos por parte del contribuyente, defraudando el código tributario, mediante modelos jurídicos arbitrarios o falsedad, evitando la conformación de actos gravados, prolongando así el origen de la imposición tributaria o mermando la base imponible. Se relaciona con la evasión de forma cercana, sin embargo, no se genera un quebrantamiento deliberado de la imposición tributaria.

La evasión de los tributos, según (Paredes, 2016) compete los actos de contravención sobre la regla fiscal, en que el desembolso por el tributo de la base imponible de un recurso es disminuido de manera parcial o total. Esta omisión de la norma se da con la reducción de las obligaciones de pago al país o aumentando los gastos deducibles que están vigentes en el Código Tributario.

En cuanto a los objetivos de la planificación tributaria estos se plantean de acuerdo con lo que se pretende lograr; los objetivos tributarios tienen la finalidad de dar cumplimiento oportuno a las obligaciones tributarias, evitando de esta manera sanciones o multas, garantizando un desarrollo convincente de la empresa en un determinado régimen impositivo, con base en políticas tributarias que estén acordes a las disposiciones señaladas en las Normas Internacionales de Información Financiera (NIIF's). Por otro lado, los objetivos económicos-financieros tienen la intención de conservar el nivel de liquidez adecuado para cubrir el pago de las obligaciones tributarias, gestar flujo de 
efectivo y definir indicadores que evalúen la eficiencia y rentabilidad para lograr un crecimiento en las empresas.

\section{Estrategias tributarias: el papel de los impuestos en la liquidez y rentabilidad de las empresas}

Las estrategias tributarias son actividades en las que se busca disminuir de una manera legal los pagos realizados al Estado por motivos de impuesto, valiéndose de herramientas que son aplicadas por personas naturales como jurídicas. Las estrategias tributarias deben ser diseñadas dependiendo de las necesidades que tiene cada empresa, ya que las compañías no son iguales y la misma táctica sería efectiva para una y no desarrollarse de buena manera en otra. Por otro lado, (Rodríguez \& Vargas, 2015) manifiesta que las estrategias tributarias son planes de acción para aprovechar los incentivos tributarios otorgados por la ley, estas estrategias comprenden el diferimiento de pagos en tributos, las depreciaciones, amortizaciones y otras exenciones y deducciones tipificadas en los artículos 9 y 10 de la Ley Orgánica de Régimen Tributario Interno.

Es por esta razón que en el transcurso del tiempo las compañías se han visto en la necesidad de mejorar sus recursos aprovechando los beneficios fiscales, mediante el empleo de estrategias tributarias en busca de optimizar los pagos de sus tributos; por cuanto los impuestos tienen incidencia en la rentabilidad operativa de las empresas mediante el uso correcto de los beneficios tributarios establecidos en la ley; en la liquidez, puesto que es la base para el cumplimiento adecuado de las obligaciones tributarias; en el endeudamiento, por cuanto limita la generación de sus propios recursos y en la captación de financiamiento mediante la aplicación eficiente del dinero entregado por parte de los inversionistas que esperan una devolución segura y ganancias concordes a su inversión. 


\section{El financiamiento: tipos y fuentes para las Pymes}

La financiación es el eje central de una micro empresa, la mayoría de empresas solicitan financiación por falta de liquidez, por lo que se convierte en una necesidad. En Latinoamérica la economía no es estable, debido a esto las Pymes necesitan de créditos para financiar sus proyectos, siendo positivo para el país pues moviliza la economía y dinamiza las fuentes de trabajo (Montoya, 2019). La financiación a plazo corto sirve como instrumento perfecto para promover la productividad en las compañías o en los negocios, da la posibilidad de tener una relación directa entre el financiamiento y los ingresos la misma que se utiliza en la consecución de un fín especifico; este tipo de financiamiento tiene un bajo riesgo para la empresa (Coronel, et al., 2020).

El financiamiento a largo plazo según (Torres, 2019), es una deuda con un ofrecimiento de cancelación superior a un año, debe solicitarlo el representante legal de la empresa bajo las disposiciones establecidas por el socio o institución bancaria que va a aportar el dinero del financiamiento, el incumplimiento de los pagos puede ocasionar la insolvencia de la compañía.

El financiamiento se obtiene por los siguientes tipos de fuentes: la financiación propia o interna es la que se produce al reinvertir las ganancias o superávit de un período contable en las organizaciones, este remanente es el fragmento correspondiente a las participaciones societarias invertidas, y, la financiación externa que procede del inversor que destina su capital con el propósito de conseguir una ganancia el momento de recuperar su dinero en el vencimiento acordado, este préstamo se observa dentro del estado de pérdidas y ganancias que tiene la organización, puesto que el interés es el beneficio que tiene el consignatario del dinero y que la empresa deberá cancelar por la usanza del capital financiado (González, 2015).

Un instrumento seguro en la evaluación del cumplimiento financiero y económico de una organización y que permite cotejar el resultado obtenido durante un período contable determinado con el de otras organizaciones que cuentan con la misma actividad, es el análisis o dictamen financiero. La importancia de este análisis es que hace posible 


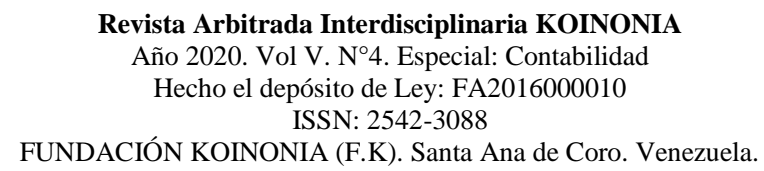

José Marcelo Casal-Abril; Jorge Edison Becerra-Molina; Lenyn Geovanny Vásconez-Acuña

reconocer la situación económica y financiera que tiene la organización con relación a la liquidez, eficacia, apalancamiento y rentabilidad, lo que permite tomar decisiones que ayuden al crecimiento de la actividad institucional (Nava-Rosillón, 2009).

El estado de situación financiera interpreta la condición económica de una organización en un período determinado, esta información se obtiene de los asientos contables de la empresa en lo que tiene que ver con el activo, pasivo y patrimonio, el nombre más utilizado para este estado es balance general. Por otro lado, el estado del resultado integral es un informe financiero que presenta de manera ordenada y clasificada los ingresos provenientes de las actividades del giro del negocio, los costos y gastos que se generen de dichas actividades en un período determinado y la utilidad o pérdida del ejercicio; la diferencia entre los ingresos y gastos constituye el rendimiento o utilidad del ejercicio económico. La utilidad del ejercicio constituye la base para el cálculo de la participación a trabajadores, luego de deducir esta, se determina el impuesto a la renta, obteniendo la utilidad neta del ejercicio (Puente, et al., 2017).

Así mismo, (Van Horne \& Wachowicz, 2010) indican que con el uso de las razones de liquidez se puede tener una perspectiva en el corto plazo de la capacidad de pago que tienen las empresas. Son utilizadas para conocer el fondo existente de dinero y en qué medida si se tiene un imprevisto las empresas son capaces de mantener su solvencia.

a) Razón corriente calcula la facultad que tiene una empresa para cubrir su deuda circulante con el valor de sus activos corrientes. (González, 2015).

b) Los activos corrientes menos los pasivos corrientes de una empresa dan como resultado su capital de trabajo; este valor debe ser favorable, si su valor es desfavorable significa que la organización en el corto plazo no tiene la liquidez suficiente para cumplir sus obligaciones (Puente, et al., 2017).

El apalancamiento de una empresa es mayor en la medida que la deuda se relaciona con el total de sus activos, los indicadores de endeudamiento miden el potencial que tiene una organización en la obtención de financiamiento sea que este provenga de sus socios 


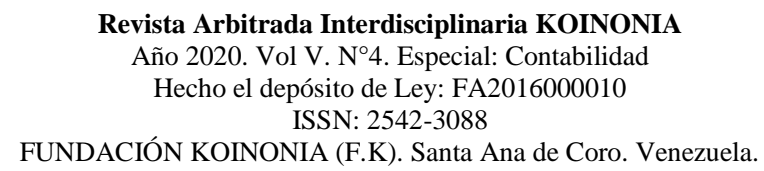

José Marcelo Casal-Abril; Jorge Edison Becerra-Molina; Lenyn Geovanny Vásconez-Acuña

o de instituciones externas tanto en el corto como en el largo plazo. (González, 2015). Entre los más relevantes se encuentran:

a) Endeudamiento del patrimonio: es la razón que se obtiene de la división de los pasivos totales de una organización y el capital invertido por sus socios, este indicador cambia dependiendo el tipo de actividad económica realizada por la empresa y los cambios en su flujo de efectivo (Van Horne \& Wachowicz, 2010).

b) Endeudamiento del activo: es la división del pasivo total de la organización para el total de sus activos, este indicador destaca el grado de financiación por medio de obligaciones adquiridas dando como resultado la proporción de activos cubiertos con el financiamiento adeudado (Van Horne \& Wachowicz, 2010).

La destreza que tiene una empresa de administrar el capital con el objetivo de conseguir las metas fijadas es conocida como la eficiencia. (Nava-Rosillón, 2009) describe a la eficiencia como la correspondencia existente entre el valor de sus transacciones y los componentes que se usaron en la producción; entre los indicadores de eficiencia más comunes se encuentran:

a) La rotación de activos totales indica la eficiencia relativa con la que una empresa utiliza sus activos para generar ventas (Puente, et al., 2017).

b) Rotación de activos fijos, este indicador se utiliza para calcular cuantas veces el activo fijo de una organización se transforma en ventas, establece la eficacia de la empresa en originar fondos mediante la inversión en activos no corrientes, un valor alto en este indicador da como resultado un manejo eficaz de las posesiones que tiene la institución. (González, 2015).

La rentabilidad según (Luciani-Toro, et al., 2019) es un instrumento aplicado a las operaciones económicas que tienen relación con los medios financieros y humanos con la finalidad de conseguir resultados, su incidencia en el negocio obedece al volumen financiero que se cuente para la cancelación de gastos de operación, inversión de proyectos y deuda. Este indicador posibilita tener en cuenta el desarrollo interno de la 
organización para optimizar su nivel de competencia en el mercado. Entre estos indicadores se encuentran:

a) Rendimiento sobre los activos (ROA) indica la fracción de la utilidad obtenida luego de impuestos por la organización tomando en cuenta la inversión realizada en activos corrientes y fijos que sirvieron para el desarrollo operativo (González, 2015).

b) Rendimiento sobre el patrimonio ( $R O E$ ) es la relación entre la utilidad después de impuestos y el capital invertido por los accionistas de la organización (Van Horne \& Wachowicz, 2010).

En la tabla 1 se presentan los distintos indicadores y sus fórmulas de cálculo:

\section{Tabla 1.}

Formulación de los indicadores financieros.

\begin{tabular}{lc}
\hline \multicolumn{1}{c}{ Indicadores } & Formulación \\
\hline Razón corriente & Activo corriente/Pasivo corriente \\
Capital de trabajo & Activo corriente-Pasivo corriente \\
Endeudamiento del patrimonio & Pasivos totales /Patrimonio \\
Endeudamiento del activo & Pasivos totales /Activos totales \\
Rotación activos totales & Ventas /Activos totales \\
Rotación activos fijos & Ventas /Activos fijos \\
ROA & Utilidad neta /Activos \\
ROE & Utilidad neta /Patrimonio \\
\hline
\end{tabular}

Fuente: Van Horne \& Wachowicz (2010).

\section{El crecimiento empresarial: estrategias y planificación}

Las empresas se erigen como actores fundamentales en el mejoramiento de la economía en las naciones, pues contribuyen a crear empleo, satisfacen necesidades, promueven procesos de innovación, contribuyen con el pago de impuestos, apoyan procesos sociales, generan excedentes y constituyen espacios para el progreso de las capacidades emprendedoras de los individuos (Rocca-Espinoza, et al., 2016). 


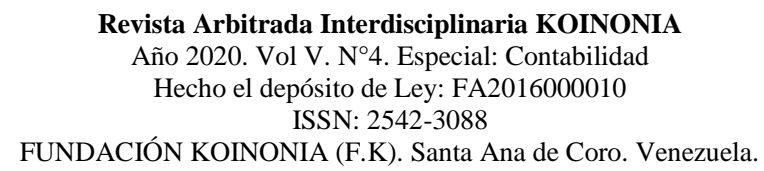

José Marcelo Casal-Abril; Jorge Edison Becerra-Molina; Lenyn Geovanny Vásconez-Acuña

Se entiende por Pymes al conglomerado de pequeñas y medianas empresas que se dedican a diversas actividades con fines específicos; en el Ecuador se encuentran en particular en la producción de bienes y servicios, siendo la base del desarrollo social por cuanto producen, demandan y compran productos o añaden valor agregado, por lo que se constituyen en actores fundamentales en la generación de riqueza y empleo (Bohórquez, et al., 2018).

En el Ecuador existen un total de 653 empresas destinadas a la actividad del alquiler de vehículos, según datos del Censo Nacional Económico que fue realizado por el Instituto Nacional de Estadísticas y Censos (INEC) en el año 2010 se encontraban inscritas 118 empresas dedicadas a esta actividad, esto quiere decir que en la última década en el país se registró un incremento aproximado de un 554\% en esta ocupación, en la ciudad de Cuenca están inscritas en la Superintendencia de Compañías, Valores y Seguros un total de 14 empresas de alquiler de vehículos.

Con respecto al crecimiento empresarial (Aguilera-Castro, 2010) lo define como un procedimiento intangible que depende de componentes tangibles como por ejemplo la acumulación de los bienes y la productividad de la gente que interviene en el proceso productivo, basado en una adecuada organización y estructura interna. (BlázquezSantana, et al., 2006) manifiestan que no se tiene unanimidad en la conceptualización del criterio del crecimiento económico entre las obras literarias de administración y economía; siendo considerado por varios autores como un propósito anhelado o el resultado de la administración eficiente en las instituciones.

Por otro lado, (Puente et al., 2017), indican que en cualquier empresa las estrategias de crecimiento empresarial tienen gran importancia. Estas estrategias tienen como intención la distribución de los recursos y fortalezas de estas instituciones con el fin de lograr sus metas de ampliación y desarrollo organizacional mediante actividades programadas con anterioridad, entre otras están las siguientes:

a) Estrategias de crecimiento intensivo: tratan de implantar las posesiones o servicios de la organización a mercados existentes de un modo intensivo. Estas estrategias 


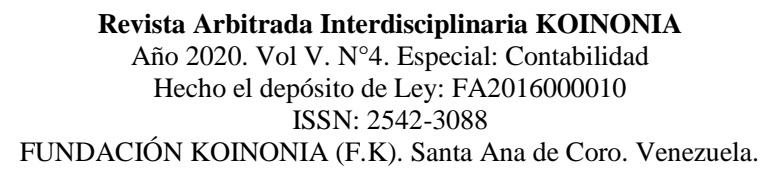

José Marcelo Casal-Abril; Jorge Edison Becerra-Molina; Lenyn Geovanny Vásconez-Acuña

son apropiadas en condiciones donde las posibilidades de producto-mercado que existen, no se han aprovechado de manera total.

b) Estrategias de crecimiento integrado: buscan beneficiarse de las fortalezas que posee una empresa en su actividad económica con el objetivo de tener control en lo que respecta a sus distribuidores, competidores y/o proveedores.

c) Estrategias de crecimiento diversificado: son apropiadas en el momento que existen escasas posibilidades de desarrollo en la actividad comercial que tiene la empresa. Esta táctica de diversificación promueve el añadir nuevos artículos o servicios a los ofrecidos con anterioridad en la empresa.

\section{MÉTODO}

La investigación se situó en una tipología descriptiva documental con diseño de campo de no experimental. La población objeto de estudio estuvo conformada por las 28 empresas de alquiler de vehículos registradas en la Superintendencia de Compañías, Valores y Seguros; la muestra de la presente investigación se estableció a través de un muestreo por conveniencia no probabilístico, el criterio establecido fue las empresas de alquiler de vehículos que se encuentran activas en la ciudad de Cuenca; la misma que estuvo conformada por las 10 empresas activas existentes. En lo que se refiere a los instrumentos, se utilizó el cuestionario que fue aplicado a los Gerentes de las empresas de alquiler de vehículos de la ciudad de Cuenca, el uso de esta herramienta posibilitó la obtención de información sobre la incidencia del financiamiento y planificación tributaria en el crecimiento de la unidad de análisis, la cual fue analizada mediante estadística descriptiva.

\section{RESULTADOS}

Para este período de diagnosis se pudo obtener la aportación de los gerentes de las empresas de alquiler de vehículos de la ciudad de Cuenca. A partir de esto, la aplicación se encaminó a establecer la incidencia que tiene el financiamiento y la planificación 


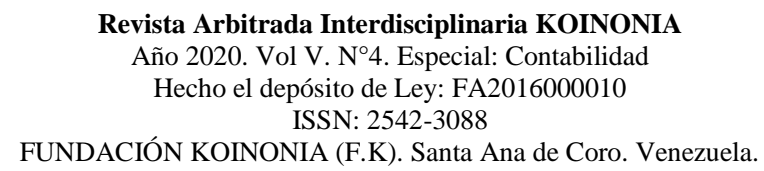

José Marcelo Casal-Abril; Jorge Edison Becerra-Molina; Lenyn Geovanny Vásconez-Acuña

tributaria en la determinación del crecimiento empresarial en las empresas de alquiler de vehículos; los resultados recabados fueron los siguientes:

Tipos y fuentes de financiamiento: el 100\% de las empresas de alquiler de vehículos de la ciudad de Cuenca solicitó financiamiento durante el año 2019, el mismo que fue utilizado en su totalidad para aumentar la flota vehicular, en vista de que de esto depende el buen giro del negocio.

En cuanto al tipo de financiamiento, el $57,1 \%$ de los gerentes utilizó el financiamiento propio con base en préstamos hechos por los socios de estas empresas los que no generan ningún tipo de intereses en comparación con entidades financieras. El $42.9 \%$ de los encuestados solicitó financiamiento externo, las mismas que consideran tener la capacidad para enfrentar este tipo de financiamiento. Del total de empresas que obtuvieron financiamiento externo el $66.67 \%$ lo realizaron con instituciones bancarias y un $33.33 \%$ con créditos directos en las concesionarias de vehículos de la ciudad de Cuenca.

Con respecto al tiempo de financiamiento, el $57.10 \%$ de las empresas solicitaron créditos a corto plazo (hasta 1 año), mientras que, el $42.9 \%$ de los gerentes eligió el financiamiento a largo plazo. Quienes solicitaron el financiamiento a corto plazo en un $75 \%$ lo hicieron por su capacidad de pago y un $25 \%$ para evitar el pago de altos intereses.

Responsabilidad tributaria: el $100 \%$ de las empresas de alquiler de vehículos encuestadas se encontraban al día en sus obligaciones tributarias. En este contexto, el $80 \%$ de los gerentes afirman no mantener obligaciones pendientes con la administración tributaria debido a la coordinación y puntualidad de los responsables de la gestión contable, en tanto que, el $20 \%$ restante afirma estar al día en sus obligaciones tributarias por el temor de ser sancionados por el Servicio de Rentas Internas (SRI); sin embargo, la totalidad de las empresas encuestadas consideran que no existen beneficios ni excepciones tributarias para este sector económico.

Así también, el 100\% de las personas encuestadas tienen conocimiento sobre la evasión y elusión tributaria, un $90 \%$ consideró que la evasión tributaria son maniobras para evitar 
el pago de impuestos, mientras que, el 10\% considera que la evasión fiscal es un acto de deshonestidad empresarial.

Crecimiento empresarial: el 100\% de los encuestados planificó con anterioridad las acciones a tomar por la empresa y definieron estrategias, con la finalidad de lograr la expansión del negocio y el crecimiento de su organización.

Así también, el $85.7 \%$ de los gerentes manifestó que las decisiones tomadas en las empresas si repercutieron en el crecimiento empresarial en el año 2019, considerando la renovación vehicular, pago de deudas adquiridas, expansión del negocio e incremento de ventas. El 14.3\% indicó que las decisiones tomadas no tuvieron ninguna repercusión en el crecimiento de su organización, pues no se obtuvo la rentabilidad planificada.

Incidencia del financiamiento en el crecimiento empresarial: el $85.7 \%$ de las empresas encuestadas, como se observa en la figura 1, indicó que el financiamiento en el año 2019 permitió el crecimiento empresarial, ya que pudieron incrementar sus activos fijos, y así lograron elevar sus ventas obteniendo una mejor utilidad. El 14.3\% indicó que durante el año 2019 no alcanzaron un crecimiento significativo.

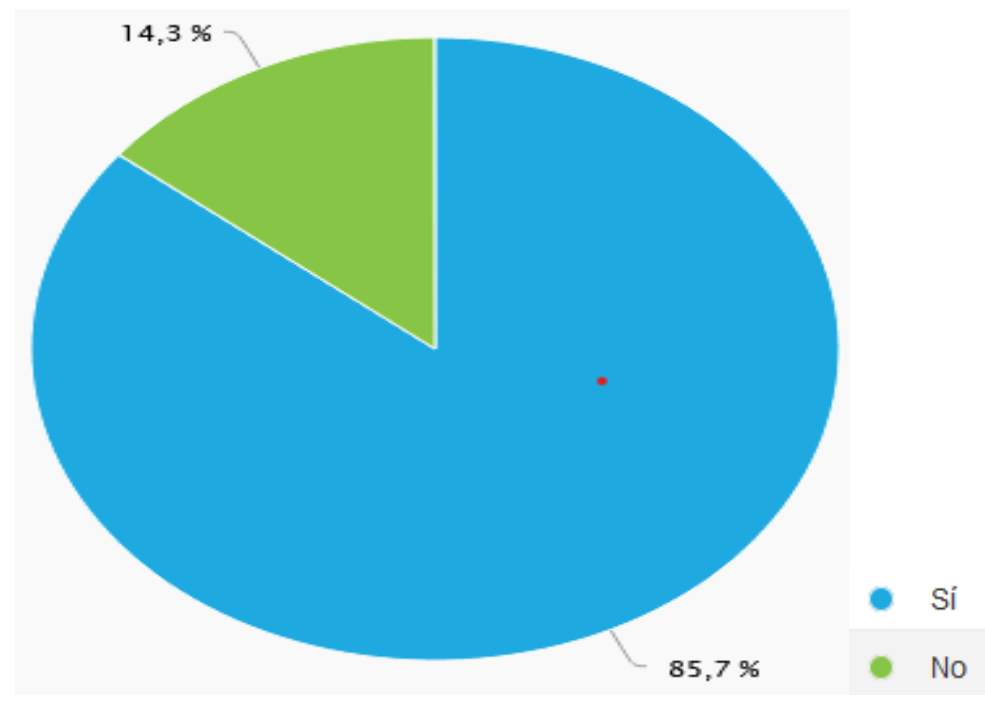

Figura 1. Incidencia del financiamiento en el crecimiento empresarial. 


\section{Incidencia de la planificación tributaria en la toma de decisiones que promuevan el} financiamiento y crecimiento empresarial: el $85.7 \%$ de los gerentes de estas empresas coincidieron en que la planificación tributaria es importante para la toma de decisiones tácticas y operativas dentro de su organización, debido a que mediante esta se maneja las oportunidades de financiamiento externo a partir del análisis comercial de las empresas, permitiendo mayor liquidez o una mejor rentabilidad financiera; el 14.3\% de los encuestados desconoce si es importante o no en su empresa la planificación tributaria. El $100 \%$ de los encuestados no aplica estrategias tributarias para mejorar el rendimiento operativo de su empresa.

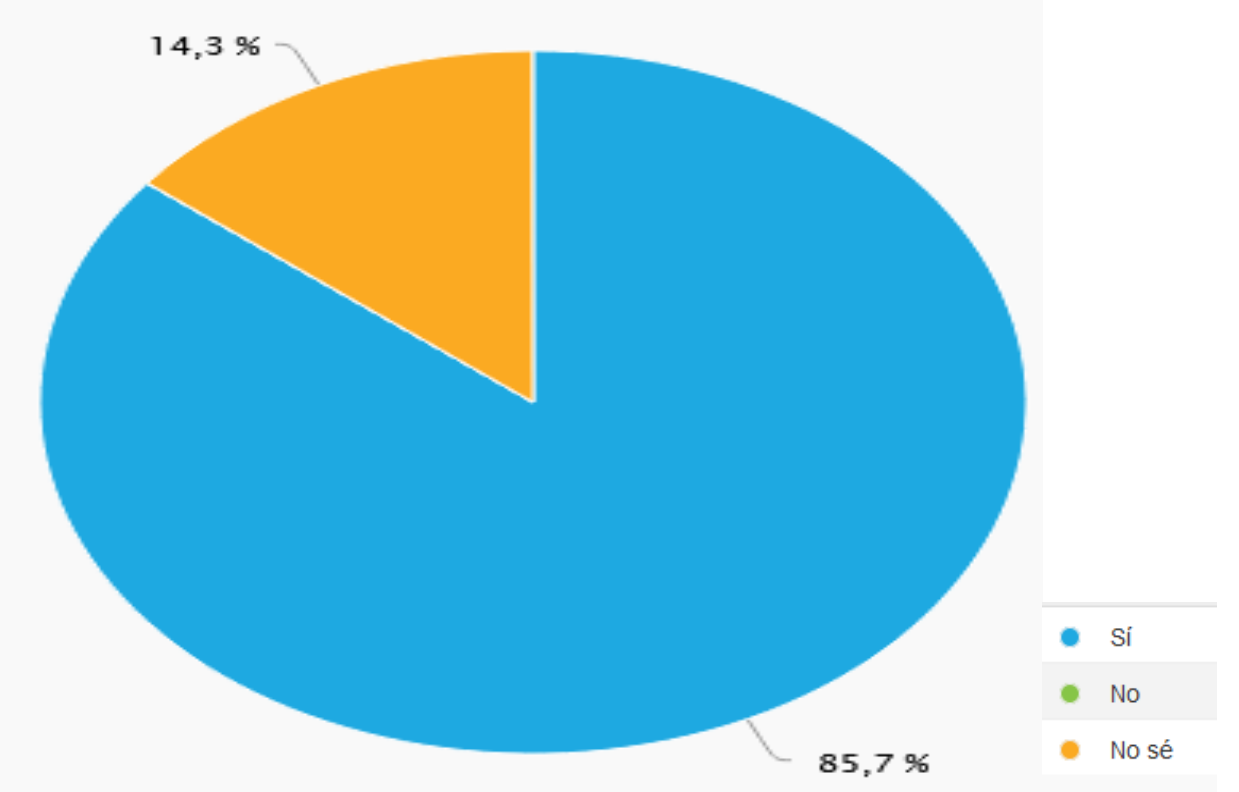

Figura 2. Incidencia de la planificación tributaria en el crecimiento empresarial. 


\section{PROPUESTA}

Conforme a los resultados que se obtuvieron en la investigación se propone un diseño de estrategias tributarias (figura 3 ) para mejorar la liquidez y rentabilidad de las empresas de alquiler de vehículos de la ciudad de Cuenca.

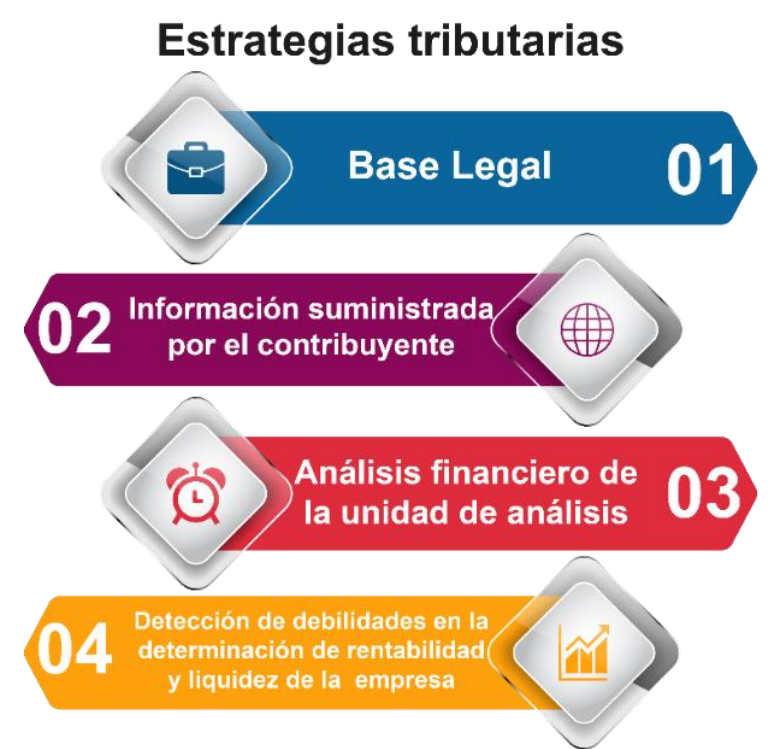

Figura 3. Diseño de estrategias tributarias que permitan el incremento de la liquidez y rentabilidad en las empresas de alquiler de vehículos de la ciudad de Cuenca. 


\section{Base legal}

La tabla 2 muestra las obligaciones tributarias que tienen este tipo de compañías con las distintas entidades facultadas para el cobro de los tributos:

Tabla 2 .

Obligaciones tributarias de las empresas de alquiler de vehículos en la ciudad de Cuenca.

\begin{tabular}{|c|c|c|c|}
\hline Impuesto & Objeto del impuesto & $\begin{array}{c}\text { Sustento } \\
\text { legal }\end{array}$ & Base imponible \\
\hline $\begin{array}{l}\text { Impuesto al } \\
\text { valor agregado } \\
\text { (IVA) }\end{array}$ & $\begin{array}{l}\text { Grava a todos los servicios, } \\
\text { entendiéndose como tales a } \\
\text { los prestados por el Estado, } \\
\text { entes públicos, sociedades, o } \\
\text { personas naturales sin } \\
\text { relación laboral, a favor de un } \\
\text { tercero, sin importar que en la } \\
\text { misma predomine el factor } \\
\text { material o intelectual, a } \\
\text { cambio de una tasa, un precio } \\
\text { pagadero en dinero, especie, } \\
\text { otros servicios o cualquier otra } \\
\text { contraprestación. }\end{array}$ & $\begin{array}{l}\text { LORTI } \\
\text { Artículo } 56 \\
\text { y } 58\end{array}$ & $\begin{array}{l}\text { Es el valor total de los bienes } \\
\text { muebles de naturaleza } \\
\text { corporal que se transfieren o } \\
\text { de los servicios que se presten, } \\
\text { calculado a base de sus } \\
\text { precios de venta o de } \\
\text { prestación del servicio, que } \\
\text { incluyen impuestos, tasas por } \\
\text { servicios y demás gastos } \\
\text { imputables al precio. El } \\
\text { porcentaje del IVA es del } 12 \% \text {. }\end{array}$ \\
\hline $\begin{array}{c}\text { Impuesto a la } \\
\text { renta }\end{array}$ & $\begin{array}{llr}\text { Tiene como objeto la renta } \\
\text { global que obtengan las } \\
\text { personas naturales, las } \\
\text { sucesiones indivisas y las } \\
\text { sociedades nacionales } \\
\text { extranjeras. }\end{array}$ & $\begin{array}{l}\text { LORTI } \\
\text { Artículos 1, } \\
2 \text { y } 37\end{array}$ & $\begin{array}{l}\text { Los ingresos gravables } \\
\text { obtenidos por sociedades } \\
\text { constituidas en el Ecuador, } \\
\text { aplicarán la tarifa del } 22 \% \text { la } \\
\text { misma que rige desde el año } \\
2013\end{array}$ \\
\hline $\begin{array}{l}\text { Impuesto a los } \\
\text { vehículos } \\
\text { motorizados }\end{array}$ & $\begin{array}{l}\text { Está destinado al transporte } \\
\text { terrestre de personas o carga, } \\
\text { tanto de uso particular como } \\
\text { de servicio público. }\end{array}$ & $\begin{array}{c}\text { Ley de } \\
\text { Reforma } \\
\text { Tributaria } \\
\text { Artículos } 1 \\
\text { y } 4\end{array}$ & $\begin{array}{l}\text { Es el avalúo de los vehículos } \\
\text { que consten en la base de } \\
\text { datos elaborada por el SRI }\end{array}$ \\
\hline
\end{tabular}




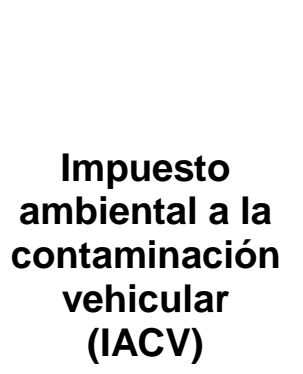

Grava la contaminación del ambiente producida por el uso de vehículos motorizados de transporte terrestre, este impuesto será cancelado por el propietario de vehículo motorizado de transporte terrestre donde el cilindraje sea mayor a $1500 \mathrm{cc}$.

El propietario de todo vehículo deberá satisfacer el impuesto anual que se determina en el

Impuesto al rodaje

Código Orgánico Territorial, Organización Autonomía Descentralización (COOTAD).
LORTI

COOTAD

Artículos

538 y 539
Es el avalúo de los vehículos que consten en la base de datos elaborada por el SRI
Está dado de acuerdo al avalúo de los vehículos que consten registrados en el Servicio de Rentas Internas y en los organismos de tránsito correspondientes
Son sujetos pasivos del impuesto, las personas naturales, jurídicas, sociedades nacionales 0

Impuesto del extranjeras, domiciliadas o

1.5 por mil con establecimiento en la sobre los respectiva jurisdicción activos totales municipal, que ejerzan de manera permanente actividades económicas.

Las, sociedades, nacionales o extranjeras, domiciliadas 0 con establecimiento en la respectiva jurisdicción municipal o metropolitana, que ejerzan actividades comerciales, industriales, financieras, inmobiliarias y profesionales

\section{COOTAD Artículo \\ El 1.5 por mil sobre los activos totales} 553
COOTAD Artículos 547 Y 548
El Concejo Cantonal mediante ordenanza establecerá la tarifa del impuesto anual en función del patrimonio de los sujetos pasivos de este impuesto 


\section{Información suministrada por el contribuyente}

La información que será solicitada a los representantes legales de estas empresas consta de la siguiente documentación:

Estatutos de las compañías: las compañías de alquiler de vehículo en su totalidad son compañías limitadas, el capital social de las mismas está dividido en participaciones por el valor de un dólar cada una, en lo que respecta a los fondos de reserva legal, estas compañías deben formar un fondo por lo menos del $20 \%$ de su capital social, segregando de manera anual el $5 \%$ de las utilidades líquidas y realizadas.

Registro único del contribuyente (RUC): se observa que este tipo de compañías se encuentran registradas como sociedades; su clase de contribuyentes es otros; la actividad económica principal es el alquiler de vehículos sin conductor.

Estado de situación financiera: mediante este estado financiero se analizan los valores de las cuentas del activo, pasivo y patrimonio de las empresas de alquiler de vehículos, para obtener las razones de los indicadores de liquidez y endeudamiento.

Estado de resultados: en este estado se consideran los valores de las ventas, gastos, utilidades antes y después de impuestos, así como el pago del impuesto a la renta que realizan estas empresas, en base a estos datos se obtienen las razones de los indicadores de eficiencia y rendimiento.

Notas a los estados financieros: sirven para conocer las políticas contables y operaciones que tiene cada empresa y de esta manera entender de forma más clara el estado de situación financiera y el estado de resultados.

Declaración del impuesto a la renta de los 3 últimos períodos: mediante estos documentos se realiza una comparación del pago de impuestos para determinar la rentabilidad de las empresas de alquiler de vehículos durante estos años, esto permite verificar si hubo un crecimiento o decrecimiento de las mismas. 


\section{Análisis financiero de la unidad de análisis}

Una vez receptados los estados financieros por parte de los contribuyentes, se procede a obtener la información necesaria (Figura 4), para realizar el cálculo de los ratios de los indicadores financieros en las empresas de alquiler de vehículos de la ciudad de Cuenca.

\begin{tabular}{|l|r|r|r|r|r|r|r|r|r|}
\hline Empresa & $\begin{array}{c}\text { Activo } \\
\text { Corriente }\end{array}$ & Activo Fijo & Total activos & $\begin{array}{c}\text { Pasivo } \\
\text { corriente }\end{array}$ & $\begin{array}{l}\text { Pasivo no } \\
\text { corriente }\end{array}$ & $\begin{array}{c}\text { Total } \\
\text { pasivos }\end{array}$ & Patrimonio & Ventas & $\begin{array}{c}\text { Utilidad } \\
\text { neta }\end{array}$ \\
\hline "Z" Cia. Ltda & $24.969,49$ & $78.229,74$ & $103.199,23$ & $13.799,22$ & $61.570,53$ & $75.369,75$ & $27.829,48$ & $146.934,63$ & $14.372,50$ \\
\hline "T" Cia. Ltda & $2.892,90$ & $49.958,31$ & $52.851,21$ & 0,00 & $51.159,80$ & $51.159,80$ & $1.691,41$ & $26.658,25$ & 269,85 \\
\hline "F" Cia. Ltda & $5.730,43$ & $58.404,15$ & $64.134,58$ & $49.168,20$ & 0,00 & $49.168,20$ & $14.966,38$ & $26.220,44$ & 893,99 \\
\hline "A" Cia. Ltda & $15.830,76$ & $150.003,71$ & $165.834,47$ & $18.671,36$ & $99.572,08$ & $118.243,44$ & $47.591,03$ & $130.446,89$ & $5.803,47$ \\
\hline "B" Cia. Ltda & $6.002,80$ & $45.332,74$ & $51.335,54$ & $4.057,45$ & $45.722,99$ & $49.780,44$ & $1.555,10$ & $29.274,50$ & 0,00 \\
\hline "D" Cia. Ltda & $41.026,31$ & $311.758,62$ & $352.784,93$ & $33.187,42$ & $224.932,86$ & $258.120,28$ & $94.664,68$ & $117.726,39$ & $4.713,98$ \\
\hline
\end{tabular}

Figura 4. Datos en dólares de los estados financieros de las empresas de alquiler de vehículos de la ciudad de Cuenca. Fuente: Superintendencia de Compañías, Valores y Seguros.

En la figura 5 se observa los ratios de los indicadores financieros de liquidez, endeudamiento, eficiencia y rentabilidad en 6 empresas de alquiler de vehículos de la ciudad de Cuenca.

\begin{tabular}{|l|r|r|r|r|r|r|r|r|}
\hline Empresa & $\begin{array}{c}\text { Razón } \\
\text { corriente } \\
\mathbf{( \$ )}\end{array}$ & $\begin{array}{c}\text { Capital de } \\
\text { trabajo (\$) }\end{array}$ & $\begin{array}{c}\text { Endeudamiento } \\
\text { del activo (\%) }\end{array}$ & $\begin{array}{c}\text { Endeudamiento } \\
\text { del patrimonio } \\
\mathbf{( \$ )}\end{array}$ & $\begin{array}{c}\text { Rotación } \\
\text { activos } \\
\text { totales (\$) }\end{array}$ & $\begin{array}{c}\text { Rotación } \\
\text { activos } \\
\text { fijos (\$) }\end{array}$ & ROA (\%) & ROE (\%) \\
\hline "Z" Cia. Ltda & 1,81 & 11170,27 & 73,03 & 2,71 & 1,42 & 1,88 & 13,93 & 51,64 \\
\hline "T" Cia. Ltda & 0,00 & 2892,90 & 96,80 & 30,25 & 0,50 & 0,53 & 0,51 & 15,95 \\
\hline "F" Cia. Ltda & 0,12 & $-43437,77$ & 76,66 & 3,29 & 0,41 & 0,45 & 1,39 & 5,97 \\
\hline "A" Cia. Ltda & 0,85 & $-2840,60$ & 71,30 & 2,48 & 0,79 & 0,87 & 3,50 & 12,19 \\
\hline "B" Cia. Ltda & 1,48 & 1945,35 & 96,97 & 32,01 & 0,57 & 0,65 & 0,00 & 0,00 \\
\hline "D" Cia. Ltda & 1,24 & 7838,89 & 73,17 & 2,73 & 0,33 & 0,38 & 1,34 & 4,98 \\
\hline
\end{tabular}

Figura 5. Cálculo de ratios financieros de liquidez, endeudamiento, eficiencia y rentabilidad de las empresas de alquiler de vehículos de la ciudad de Cuenca 
En la figura 6, se muestra el impuesto a la renta causado por las empresas de alquiler de vehículos en los períodos fiscales 2016, 2017 y 2018.

\begin{tabular}{|c|r|r|r|}
\hline Empresa & \multicolumn{1}{|c|}{$\mathbf{2 0 1 6}$} & \multicolumn{1}{c|}{$\mathbf{2 0 1 7}$} & \multicolumn{1}{c|}{$\mathbf{2 0 1 8}$} \\
\hline "Z" Cia. Ltda & 0,00 & $1.720,14$ & $4.053,78$ \\
\hline "T" Cia. Ltda & 56,41 & 15,89 & 76,11 \\
\hline "F" Cia. Ltda & 213,06 & 702,96 & 252,15 \\
\hline "A" Cia. Ltda & 887,15 & 981,00 & $1.432,35$ \\
\hline "B" Cia. Ltda & 383,32 & 349,77 & 0,00 \\
\hline "D" Cia. Ltda & $3.309,69$ & $2.535,93$ & $1.329,58$ \\
\hline
\end{tabular}

Figura 6. Impuesto a la renta causado en las empresas de alquiler de vehículos de la ciudad de Cuenca.

Fuente: Superintendencia de Compañías, Valores y Seguros.

\section{Detección de debilidades en la determinación de rentabilidad y liquidez de la empresa}

Para la determinación de las estrategias tributarias como herramientas de optimización en la liquidez y rentabilidad en las empresas de alquiler de vehículos de la ciudad de Cuenca se realizó una agrupación de acuerdo a su nivel de ventas:

En la tabla 3 se presentan estrategias tributarias para las empresas de alquiler de vehículos que cuentan con un nivel de ventas igual o menor a los 100.000 dólares. 
Tabla 3.

Estrategias tributarias para las empresas con ventas igual o menor a 100.000 dólares.

\begin{tabular}{|c|c|c|c|c|}
\hline Empresas & Deficiencias & Estrategias & $\begin{array}{l}\text { Sustento } \\
\text { legal del } \\
\text { beneficio }\end{array}$ & $\begin{array}{l}\text { Tiempo de } \\
\text { ejecución }\end{array}$ \\
\hline \multirow{3}{*}{$\begin{array}{l}\text { "B”, “F" y } \\
\text { “T” Cía. } \\
\text { Ltda. }\end{array}$} & $\begin{array}{l}\text { Empresas no cuentan } \\
\text { con personal acorde } \\
\text { para promocionar su } \\
\text { actividad económica } \\
\text { principal y solo se } \\
\text { sujetan a los clientes } \\
\text { que llegan directo a } \\
\text { sus locales. }\end{array}$ & $\begin{array}{l}\text { Contratar } 1 \text { persona mayor de } \\
40 \text { años que haya retornado } \\
\text { del exterior la misma que } \\
\text { buscará convenios con hoteles } \\
\text { de la ciudad para captar } \\
\text { clientes, con esta contratación } \\
\text { podrá deducir un } 150 \% \\
\text { adicional del pago del } \\
\text { impuesto a la renta por los } \\
\text { beneficios sociales y } \\
\text { remuneraciones canceladas } \\
\text { por un período de } 2 \text { años } \\
\text { desde la firma del contrato. }\end{array}$ & $\begin{array}{c}\text { LORTI } \\
\text { Artículo } 10 \\
\text { numeral } 9\end{array}$ & $\begin{array}{l}\text { Se } \\
\text { recomienda } \\
\text { contratarlo } \\
\text { de manera } \\
\text { inmediata }\end{array}$ \\
\hline & $\begin{array}{l}\text { Para el pago del } \\
\text { impuesto a la renta no } \\
\text { se está considerando } \\
\text { el valor de la prima de } \\
\text { los seguros de los } \\
\text { vehículos los mismos } \\
\text { que son bienes que } \\
\text { integran la actividad } \\
\text { generadora del } \\
\text { ingreso gravable. }\end{array}$ & $\begin{array}{l}\text { Realizar el devengado de la } \\
\text { prima del seguro de los } \\
\text { vehículos de estas compañías } \\
\text { que sirven como deducible del } \\
\text { pago del impuesto a la renta. }\end{array}$ & $\begin{array}{c}\text { LORTI } \\
\text { Artículo } 10 \\
\text { numeral } 4\end{array}$ & $\begin{array}{l}\text { Se } \\
\text { recomienda } \\
\text { realizarlo a } \\
\text { partir de } \\
\text { este período } \\
\text { fiscal }\end{array}$ \\
\hline & $\begin{array}{l}\text { Se evidencio que las } \\
\text { facturas por gastos de } \\
\text { entregas de los } \\
\text { vehículos en otras } \\
\text { ciudades del país no } \\
\text { se están realizando a } \\
\text { nombre de las } \\
\text { compañías. }\end{array}$ & $\begin{array}{l}\text { Las facturas de los gastos por } \\
\text { viaje y estadía deben } \\
\text { registrarse a nombre de la } \\
\text { compañía respectiva, con esto } \\
\text { se deberá aplicar la retención } \\
\text { correspondiente lo que servirá } \\
\text { para deducir el impuesto a la } \\
\text { renta y tendrá derecho a } \\
\text { crédito tributario. }\end{array}$ & $\begin{array}{c}\text { LORTI } \\
\text { Artículo } 10 \\
\text { numeral } 6\end{array}$ & $\begin{array}{l}\text { De manera } \\
\text { inmediata }\end{array}$ \\
\hline
\end{tabular}


En la tabla 4 se plantean estrategias tributarias para las empresas de alquiler de vehículos que cuentan con un nivel de ventas mayor a los 100.000 dólares.

Tabla 4.

Estrategias tributarias para las empresas con ventas mayores a 100.000 dólares.

\begin{tabular}{|c|c|c|c|c|}
\hline Empresas & Deficiencias & Estrategias & $\begin{array}{c}\text { Sustento } \\
\text { legal }\end{array}$ & $\begin{array}{l}\text { Tiempo de } \\
\text { ejecución }\end{array}$ \\
\hline \multirow{3}{*}{$\begin{array}{l}\text { "A", "D" } \\
\text { y “Z" } \\
\text { Cías. } \\
\text { Ltda. }\end{array}$} & $\begin{array}{l}\text { Las empresas cuentan } \\
\text { con un buen flujo de } \\
\text { efectivo lo que se } \\
\text { mantiene en la cuenta } \\
\text { sin tener ningún } \\
\text { beneficio a cambio. }\end{array}$ & $\begin{array}{l}\text { Destinar una parte del } \\
\text { efectivo en depósitos a } \\
\text { plazo fijo en instituciones } \\
\text { financieras manteniendo } \\
\text { las mismas por lo menos } \\
360 \text { días de forma continua, } \\
\text { ocasionando que el valor } \\
\text { del rendimiento obtenido } \\
\text { sea un deducible del } \\
\text { impuesto a la renta. }\end{array}$ & $\begin{array}{c}\text { LORTI } \\
\text { Artículo } 9 \\
\text { numeral } 15\end{array}$ & $\begin{array}{l}\text { Se recomienda } \\
\text { realizarlo } \\
\text { desde el } 1 \text { de } \\
\text { enero del } \\
\text { siguiente } \\
\text { período fiscal. }\end{array}$ \\
\hline & $\begin{array}{l}\text { La depreciación de los } \\
\text { vehículos está siendo } \\
\text { calculada mediante el } \\
\text { método de línea recta, } \\
\text { cuando los vehículos } \\
\text { por motivo del giro de } \\
\text { negocio deben } \\
\text { cambiarse cada } 4 \text { o } 5 \\
\text { años. }\end{array}$ & $\begin{array}{l}\text { Cambiar el método de } \\
\text { depreciación al método } \\
\text { decreciente o acelerado, } \\
\text { esto hace posible que en } \\
\text { los primeros años se } \\
\text { deduzca un valor mayor en } \\
\text { el impuesto a la renta. }\end{array}$ & $\begin{array}{c}\text { LORTI } \\
\text { Artículo } 10 \\
\text { numeral } 7\end{array}$ & $\begin{array}{l}\text { Se recomienda } \\
\text { utilizar este } \\
\text { método a partir } \\
\text { de la compra } \\
\text { de nuevos } \\
\text { vehículos para } \\
\text { el giro del } \\
\text { negocio. }\end{array}$ \\
\hline & $\begin{array}{l}\text { Los socios de estas } \\
\text { empresas solicitan } \\
\text { préstamos bancarios } \\
\text { para compra de } \\
\text { vehículos a nombre } \\
\text { personal y no de la } \\
\text { compañía. }\end{array}$ & $\begin{array}{l}\text { Solicitar la financiación para } \\
\text { la adquisición de vehículos } \\
\text { a nombre de la empresa, } \\
\text { con esto se podrán deducir } \\
\text { del pago del impuesto a la } \\
\text { renta los intereses } \\
\text { ocasionados por motivos } \\
\text { del préstamo. }\end{array}$ & $\begin{array}{c}\text { LORTI } \\
\text { Artículo } 10 \\
\text { numeral } 18 \\
\text { literal } 3\end{array}$ & $\begin{array}{c}\text { De manera } \\
\text { inmediata }\end{array}$ \\
\hline
\end{tabular}


Revista Arbitrada Interdisciplinaria KOINONIA

Año 2020. Vol V. N ${ }^{\circ}$. Especial: Contabilidad

Hecho el depósito de Ley: FA2016000010

ISSN: 2542-3088

FUNDACIÓN KOINONIA (F.K). Santa Ana de Coro. Venezuela.

José Marcelo Casal-Abril; Jorge Edison Becerra-Molina; Lenyn Geovanny Vásconez-Acuña

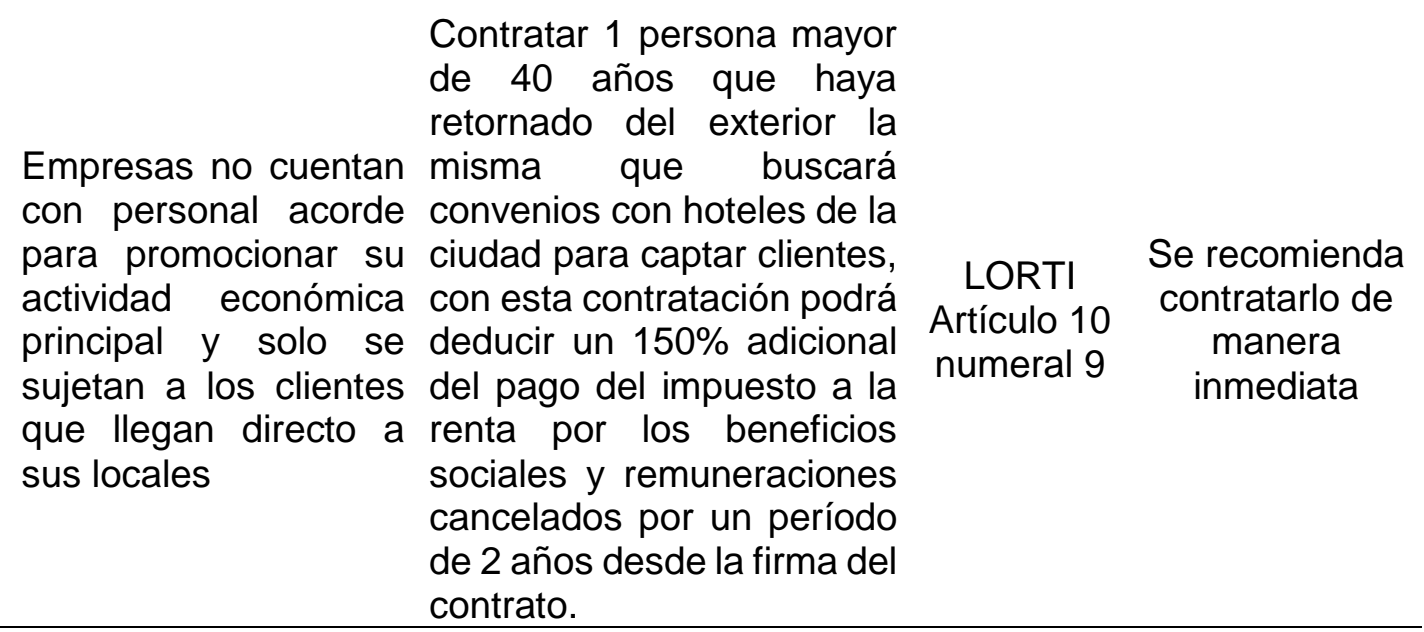

En la figura 7, se describen las cuentas contables afectadas con la implementación de las estrategias tributarias:

\begin{tabular}{|c|c|c|}
\hline Estrategias & Debe & Haber \\
\hline $\begin{array}{l}\text { Contratar } 1 \text { persona mayor de } 40 \text { años que haya retornado del exterior la misma que } \\
\text { buscará convenios con hoteles de la ciudad para captar clientes, con esta } \\
\text { contratación podrá deducir un } 150 \% \text { adicional del pago del impuesto a la renta por los } \\
\text { beneficios sociales y remuneraciones canceladas por un periodo de } 2 \text { años desde la } \\
\text { firma del contrato. }\end{array}$ & Sueldos y salarios & $\begin{array}{l}\text { Efectivo y sus } \\
\text { equivalentes }\end{array}$ \\
\hline $\begin{array}{l}\text { Realizar el devengado de la prima del seguro de los vehículos de estas compañías } \\
\text { que sirven como deducible del pago del impuesto a la renta. }\end{array}$ & $\begin{array}{l}\text { Seguros y } \\
\text { reaseguros }\end{array}$ & $\begin{array}{l}\text { Seguros pagados } \\
\text { por anticipado }\end{array}$ \\
\hline $\begin{array}{l}\text { Las facturas de los gastos por viaje y estadía deben registrarse a nombre de la } \\
\text { compañía respectiva, con esto se deberá aplicar la retención correspondiente lo que } \\
\text { servirá para deducir el impuesto a la renta y tendrá derecho a crédito tributario. }\end{array}$ & Gastos de viaje & $\begin{array}{l}\text { Efectivo y sus } \\
\text { equivalentes }\end{array}$ \\
\hline $\begin{array}{l}\text { Destinar una parte del efectivo en depósitos a plazo fijo en instituciones financieras } \\
\text { manteniendo las mismas por lo menos } 360 \text { dias de forma continua, ocasionando que } \\
\text { el valor del rendimiento obtenido sea un deducible del impuesto a la renta. }\end{array}$ & $\begin{array}{l}\text { Efectivo y sus } \\
\text { equivalentes }\end{array}$ & Intereses ganados \\
\hline $\begin{array}{l}\text { Cambiar el método de depreciación al método decreciente o acelerado, esto hace } \\
\text { posible que en los primeros años se deduzca un valor mayor en el impuesto a la renta }\end{array}$ & $\begin{array}{l}\text { Depreciación } \\
\text { vehículos }\end{array}$ & $\begin{array}{l}\text { Depreciación } \\
\text { acumulada de } \\
\text { vehículos }\end{array}$ \\
\hline $\begin{array}{l}\text { Solicitar la financiación para la adquisición de vehículos a nombre de la empresa, con } \\
\text { esto se podrán deducir del pago del impuesto a la renta los intereses ocasionados } \\
\text { por motivos del préstamo. }\end{array}$ & $\begin{array}{l}\text { Intereses con } \\
\text { instituciones } \\
\text { financieras }\end{array}$ & $\begin{array}{l}\text { Efectivo y sus } \\
\text { equivalentes }\end{array}$ \\
\hline
\end{tabular}

Figura 7. Afectación de cuentas contables. 


\section{CONCLUSIONES}

El financiamiento en las empresas de alquiler de vehículos, es uno de los pilares fundamentales para que estas empresas incrementen su flota vehicular, lo que significará obtener mayores ingresos mejorando de esta manera su rentabilidad, los ratios financieros de la mayoría de estas empresas demuestran una liquidez baja, ya que los créditos otorgados por las instituciones financieras en un porcentaje alto son negados. En cuanto a la planeación tributaria es importante que los gerentes tengan conocimiento de las estrategias tributarias que benefician a estas empresas, esto permitirá que las decisiones tomadas sean acertadas, generando una mejora en el pago de sus impuestos que se convierte en un factor clave para lograr una gestión eficiente en busca de obtener mayores ingresos para conseguir un crecimiento empresarial.

El financiamiento tiene una incidencia directa en el crecimiento empresarial, estas empresas surgen en su mayoría con préstamos realizados por sus socios o accionistas que buscan recuperar su inversión en un corto plazo, esta inyección de dinero permitió de forma moderada el incremento de los activos fijos (vehículos) de estas empresas, logrando que exista utilidad en las mismas.

La responsabilidad que tienen las empresas de alquiler de vehículos en cuanto al cumplimiento de las obligaciones tributarias que han sido dispuestas en la ley, se ha logrado en base a la planificación tributaria, puesto que les ha permitido estar al día con el Servicio de Rentas Internas, evitando el aplazamiento y cualquier recargo establecido por la administración tributaria.

La propuesta de diseñar estrategias tributarias como herramientas de optimización de rentabilidad, busca identificar las exenciones y deducciones contempladas en la Ley Orgánica de Régimen Tributario Interno que las empresas de alquiler de vehículos deben utilizar para beneficiarse de un menor pago del impuesto a la renta.

Por medio del diseño de estas estrategias se pretende disminuir la carga de impuestos de una manera licita sin caer en la elusión o evasión de impuestos que son sancionadas 
por la ley, sino más bien, consiste en utilizar los medios que brinda el ordenamiento jurídico o de una deficiencia en la norma.

\section{FINANCIAMIENTO}

No monetario.

\section{AGRADECIMIENTO}

A las empresas de alquiler de vehículos registradas en la Superintendencia de Compañías, Valores y Seguros de la ciudad de Cuenca, Ecuador; por su disponibilidad en el desarrollo de la investigación.

\section{REFERENCIAS}

Aguilera-Castro, A. (2010). Direccionamiento estratégico y crecimiento empresarial: algunas reflexiones en torno a su relación. [Strategic direction and entrepreneurial growth: some reflections on their relationship]. Pensamiento \& Gestión, (28), 85106.

Amasifuen, M. (2015). Importancia de la cultura tributaria en el Perú. [Importance of tax culture in Peru]. Accounting Power for Business, 1(1); 73-90.

Báez, T. (2016). Planificación tributaria, herramienta fundamental en todo negocio. [tax planning, a fundamental tool in every business]. Recuperado de https://n9.cl/dikh

Blázquez-Santana, F., Dorta-Velázquez, J., \& Verona-Martel, M. (2006). Factores del crecimiento empresarial. Especial referencia a las pequeñas y medianas empresas [Factors of business growth. Special reference to small and medium-sized companies]. Innovar, 16(28), 43-56.

Bohórquez, N. M., López, A. S., \& Castañeda, L. (2018). Fuentes de financiamiento para PYMES y su incidencia en la toma de decisiones financieras [Sources of financing for SMEs and their impact on financial decision-making]. [Internet]. Revista Observatorio de la Economía Latinoamericana. Recuperado de https://n9.cl/hfdu 
Castañeda-Rodríguez, V. (2017). La equidad del sistema tributario y su relación con la moral tributaria. Un estudio para América Latina. [The fairness of the tax system and its relationship with tax morality. A study for Latin America]. Investigación económica, 76(299), 125-152.

Coronel-Rodríguez, E., Narváez-Zurita, C., \& Erazo-Álvarez, J. (2020). Evaluación del proceso de planificación y del ciclo presupuestario para los Gobiernos Autónomos Descentralizados. [Evaluation of the planning process and budget cycle for the Decentralized Autonomous Governments]. Revista Arbitrada Interdisciplinaria Koinonía, 5(10), 63-91. http://dx.doi.org/10.35381/r.k.v5i10.688

Daza-Izquierdo, J. (2016). Crecimiento y rentabilidad empresarial en el sector industrial brasileño. [Firm growth and profitability for the industrial sector in Brazil]. Contaduría y administración, 61(2), 266282. https://doi.org/10.1016/i.cya.2015.12.001

García T., Galo H., \& Villafuerte O., Marcelo F. (2015). Las restricciones al financiamiento de las PYMES del Ecuador y su incidencia en la política de inversiones. [Restrictions on financing for SMEs in Ecuador and their impact on investment policy]. Actualidad Contable Faces, 18(30),49-73.

González, S. M. (2015). La gestión financiera y el acceso a financiamiento de las Pymes del sector comercio en la ciudad de Bogotá. [Financial management and access to financing for SMEs in the commercial sector in the city of Bogotá]. Tesis de magister. Universidad Nacional de Colombia. Recuerado de https://n9.cl/zt2e

Luciani-Toro, L, Zambrano-Morales, Á, \& González-Ordoñez, A. (2019). MIPYMES ecuatorianas: Una visión de su emprendimiento, productividad y competitividad en aras de mejora continua. [Ecuadorian MIPYMES: A vision of their entrepreneurship, productivity and competitiveness for the sake of continuous improvement]. Cooperativismo y Desarrollo, 7(3), 313-332.

Matus-Fuentes, M. (2017). La elusión tributaria y su sanción en la Ley № 20.780: Hacia un concepto de negocio jurídico elusivo. [Tax avoidance and its sanction in Law No. 20,780: Towards an elusive legal business concept]. Ius et Praxis, 23(1), 6790. https://dx.doi.org/10.4067/S0718-00122017000100003

Montoya, L. E. (2019). Préstamo back to back como alternativa de financiamiento a corto plazo para las empresas privadas del sector comercial en Guayaquil. [Back to back loan as a short-term financing alternative for private companies in the commercial sector in Guayaquil\}. Recuperado de https://n9.cl/i9ms 
Nava-Rosillón, M. (2009). Análisis financiero: una herramienta clave para una gestión financiera eficiente [Financial analysis: a key tool for efficient financial management]. Revista Venezolana de Gerencia, 14(48),606-628.

Paredes, P. (2016). Evasión Tributaria vs Mecanismos implementados por la Administración Pública [Tax Evasion vs. Mechanisms implemented by the Public Administration]. Retos, 6(12), 181-198. https://doi.org/10.17163/ret.n12.2016.04

Paredes, P. (2016). Evasión tributaria vs. mecanismos de control implementados por la administración pública [Tax evasion vs. control mechanisms implemented by the public administration]. RETOS. Revista de Ciencias de la Administración y Economía, 6(12),179-198.

Puente, M., Viñán, J., \& Aguilar, J. (2017). Planeación financiera y presupuestaria [Financial and budgetary planning]. Riobamba: Escuela Superior Politécnica de Chimborazo. Recuperado de https://n9.cl/c9jpi

Registro Oficial Suplemento 38 de 14-jun.-2005. Código Tributario [Tributary Code]. Recuperado de https://n9.cl/k8gl

Registro Oficial Suplemento 463 de 17-nov-2014. Ley Orgánica de Régimen Tributario Interno [Organic Law of Internal Tax Regime]. Recuperado de https://n9.cl/evu4

Rocca-Espinoza, E, \& García-Pérez-de-Lema, D, \& Gómez-Guillamón, A. (2016). Factores determinantes del éxito competitivo en la mipyme: un estudio empírico en empresas peruanas [Determinants of competitive success in MSMEs: an empirical study in Peruvian companies]. Contabilidad y Negocios, 11(22),52-68.

Rodríguez, E, \& Vargas, W. (2015). Estrategias de control fiscal para la recaudación tributaria de un órgano municipal [Fiscal control strategies for tax collection of a municipal body]. Negotium, 11(31),3-23.

Sarduy-González, M, \& Gancedo-Gaspar, I. (2016). La cultura tributaria en la sociedad cubana: un problema a resolver [Taxpaying Culture in Cuban Society: a Problem to Solve]. Cofin Habana, 10(1), 113-125.

Soto, M. (2018). Tributación justa y el crecimiento económico de las micro y pequeñas empresas Mypes fabricantes de prendas de vestir de la Región Junín. [Fair taxation and economic growth of micro and small companies Mypes garment manufacturers in the Junín Region]. Recuperado de https://n9.cl/984zC 
Torres, E. (2019). Financiamiento, Rentabilidad Y Tributación de la micro y pequeña empresa del sector comercio "Distribuidora Valky office" S.A.C. [Financing, Profitability and Taxation of the micro and small business sector "Distribuidora Valky office" S.A.C.]. Recuperado de https://n9.cl/owo9

Van Horne, J., \& Wachowicz, J. (2010). Fundamentos de Administración Financiera [Fundamentals of Financial Administration]. México: Pearson Educación.

Veloz-García, B. (2018). Análisis tributario y su concurrencia en las obligaciones tributarias de las PYMES del cantón Milagro en el año 2017. [Tax analysis and its concurrence in the tax obligations of the SMEs of the canton Milagro in the year 2017]. Recuperado de https://n9.cl/ezouh 